\title{
PLANTS OF THE NEW ALBANY SHALE. III: CHAPELIA CAMPBELLII GEN. N.'
}

\author{
Charles B. Beck and Robert E. Bailey \\ Department of Botany, University of Michigan, Ann Arbor
}

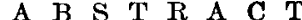

\begin{abstract}
The single specimen from the Falling Run Member of the Sanderson Formation is interpreted as a segment of a petiole from a region just proximal to a major branching of the frond. The specimen is characterized, basally, by a four-lobed primary xylem strand. Following stelar branching there are two outer papilionoid strands that produce alternate traces bilaterally and two inner clepsydroid strands, oriented at right angles to the plane of the frond. The frond, which appears to be a morphologically flattened and modified lateral branch system, is probably of calamopityean or pteridosperm affinity.
\end{abstract}

It is Often Difficule, if not impossible, to distinguish between cauline and foliar axes in primitive plants. Considerable evidence suggests that leaves have evolved by modification of lateral branch systems. If this is true, it is to be expected that primitive leaves will have some stem-like characteristics. The structure of Tetraxylopteris schmidtii (Beck, 1957), a presumed progymnosperm and possible pteridosperm precursor, emphasizes this problem and illustrates a primitive condition in the evolutionary differentiation of leaf and stem. In this plant the cruciform primary xylem strand of axes considered to be the "rachises" is repeated in the primary and secondary "pinna" axes of lateral branch systems which seem functionally to be leaves (fronds). These "fronds" are, however, radially symmetrical with both primary and secondary pinna axes being disposed in an opposite and decussate manner. There are no laminae produced in this system, the terminal branches being small, terete segments produced by one or two dichotomies. These branch systems, interpreted as homologous with leaves, are therefore predominantly stem-like.

This problem has again been emphasized by A. G. Long's work on Tristichia ovensi. In Tristichia small laminae are apparently produced only terminally, the large part of the fronds consisting of naked axes. Long (1961) stresses the great difficulty in distinguishing between stems and petioles in compression specimens, but in petrifactions he identifies the axes with internal structure of radial symmetry (reflected externally by a radial arrangement of lateral appendages) as stems, and those with bilateral symmetry as

1 Received for publication 17 October 1966.

Supported by National Science Foundation - Grant, GB-3038.

The final rendering of Fig. 27 is the work of Mr. Derwin Bell, Department of Geology, University of Michigan.

The authors thank Dr. Francis Hucber of the U. S. National Museum for loan of the type slides of Stenomyelon muratum. petioles. Gordon (1938) similarly distinguished stems and petioles of Tetrastichia. These criteria are based on the condition in plants in which leaves and stems are well defined. In view of the structure of the frond-like branch systems of Tetraxylopteris, it seems reasonable to suspect that this might not, however, be a valid basis for making such a distinction in primitive plants. This view gains additional support from a recent study of Long (1963) in which he suggests that Tristichia ovensi may, in fact, be the ovuliferous part of the fronds of Pitys.

Chapelia, the new genus described in this paper, provides additional evidence that strongly reinforces this view. It represents part of a frond axis that combines distinctly stem-like characteristics with distinctly leaf-like characteristics. It is further remarkable in that in stelar anatomy and in other aspects of internal structure it combines to some degree the characters of several genera, including Lyginorachis, Clepsydropsis, Tetrastichia, Tristichia, and the StenomyelonCalamopitys complex.

The single, well-preserved petrifaction of Chapelia campbellii was collected from the uppermost part of the New Albany Shale near Jacobs Chapel north of New Albany, Ind. The excellence of preservation is related to the fact that it was contained in an unweathered nodule quarried directly from the shale in the bed of Lewis Branch. From this specimen 30 transverse thinsections were prepared. All of the photography with the exception of Fig. 23-26 has been accomplished using reflected light.

Description-The specimen, about $2.5 \mathrm{~cm}$ long and about $5 \mathrm{~mm}$ in diam at the base, was partially decorticated prior to preservation, and none of the epidermis or outer cortex is preserved (Fig. 1). The branching of the stele clearly suggests that it comes from a region just below a level of branching of the petiole as shown in the 
reconstruction (Fig. 27). The specimen contains secondary as well as primary tissues. The column of primary xylem at the base is vaguely fourlobed in transverse section (Fig. 18) and it broadens, becoming distinctly four-lobed prior to branching of the vascular column (Fig. 1, 20, 21). It is partly surrounded, in the base of the specimen, by parenchyma which in turn is enclosed by secondary xylem (Fig. 1, 18, 20, 21). Following branching, the parenchyma separating the primary and secondary xylem is no longer retained (Fig. 4-8, 22, 27). Primary xylem in the branches occurs in two cross-sectional forms. It is papilionoid in the two outer vascular columns which are about $1.8 \mathrm{~mm}$ in diam, and clepsydroid in the two inner ones which are about $1.3 \mathrm{~mm}$ in diam (Fig. 4-8, 14-17, 22, 27). A narrow band of phloem is preserved in some regions and is pnclosed bv cortex (Fig. 1, 18, 23).

Primary xylem-This tissue consists of both tracheids and parenchyma with parenchyma occurring in both protoxylem and metaxylem (Fig. 6, 9, 20). Development of primary xylem is mesarch, there being one or two protoxylems in each lobe of the primary xylem column (Fig. $10-18,20)$. Cells of the metaxylem are typically angular in transverse view and average $50 \mu$ in diam. Protoxylem cells of similar shape have a mean diameter of $14 \mu$ (Fig. 6, 20).

Cells of the parenchyma surrounding the primary xylem are of similar transverse size to those of the metaxylem, averaging about $50 \mu$ in diam. These cells are thin-walled and are oval to angular in sectional view (Fig. 20). Although in some sections this parenchyma is rather extensive, in none is the primary and secondary xylem completely separated.

Secondary xylem - At the base of the specimen there is a large amount of secondary xylem which forms a cylinder about $0.9 \mathrm{~mm}$ in thickness (Fig. $1,18)$. Secondary xylem persists throughout the entire length of the specimen, but gradually decreases in amount distally (Fig. 1-5, 10-17, 27).

This tissue consists of rather broad tracheids, generally rectangular to hexagonal in transverse shape (Fig. 23), with a mean diameter of $55 \mu$. The rays are uniseriate near the pith (Fig. 20), but some become biseriate and quite wide $(57 \mu)$ toward the outer boundary of the secondary xylem, this and the rather broad tracheids giving it a somewhat manoxylic appearance (Fig. 23).

Secondary phloem-Rays extend from the secondary xylem into the phloem, indicating its secondary nature (Fig. 23). In addition to the rays, there are radially arranged, thin-walled cells, similar in size and shape to the secondary tracheids. Bounding this region are clusters of very thick-walled fiber-like cells about $57 \mu$ in mean diam (Fig. 23). The possibility that these are sclereids cannot be ruled out since they have not been observed in longitudinal section. These may represent primary phloem.

Cortex-Only fragments of the cortex are preserved (Fig. 1). It consists of a ground tissue of large, thin-walled parenchyma ells, angular in transverse outline, that average $87 \mu$ in diam (Fig. 1, 4, 19, 24). Within the outer part of this tissue there are clusters of cells of sclerotic appearance that seem to be oriented tangentially, forming a cylinder (Fig. 19, 26). In addition, there are smaller groups and of ten single cells of similar appearance that are clearly the remains of some type of thick-walled sclerenchyma (Fig. 1, 4, 24, $25)$. The thick wall, however, exhibits varying degrees of degradation (Fig. 24, 25). It is best preserved in the cells nearest the center of the axis, and usually least preserved in the outer part of the cortex. When nearly completely degraded the cells appear to have only a very thin wall and to be filled with some sort of dark cell content (Fig. 24). In this condition they resemble the so-called "secretory sacs" or cells described by various workers in the petioles of Lyginopteris (Williamson, 1890; Williamson and Scott, 1895), Tetrastichia (Gordon, 1938), Tristichia (Long, 1961), and most species of Lyginorachis (see Scott, 1923; Crookall, 1931). The larger "clusters" also occasionally contain a few cells with thick walls, which seem clearly to be sclerenchymatous (Fig. 25). It is very likely that the dark content of the cells in these clusters is also degraded cell wall, which suggests that the clusters were originally composed entirely of sclerenchyma. These clusters resemble the "sclerotic nests" described in some pteridosperm petioles, especially if this interpretation is correct.

Branching of the vascular column-We have interpreted the primary vascular strand at the base of the specimen to be four-lobed in sectional view. If some of the parenchyma that accompanies the strand is part of the primary xylem, then it might be described more accurately as broadly triangular or three-lobed (Fig. 18). The presence of four protoxylems, however, suggests that the former interpretation is probably the more correct one, but it does not rule out the possibility that the strand might have been distinctly three-lobed and triarch at a lower level. Prior to branching the primary xylem strand broadens and becomes more distinctly four-lobed (Fig. 1).

Branching of the vascular column takes place in two planes, the first an equal branching in the plane of the presumed frond (Fig. 1-3, 11-13), and the second - which begins before the first is completed - an unequal branching of each column in parallel planes oriented obliquely to the first (Fig. 2-4, 12-14). One of the smaller of the two axes produced by this second branching is pro- 


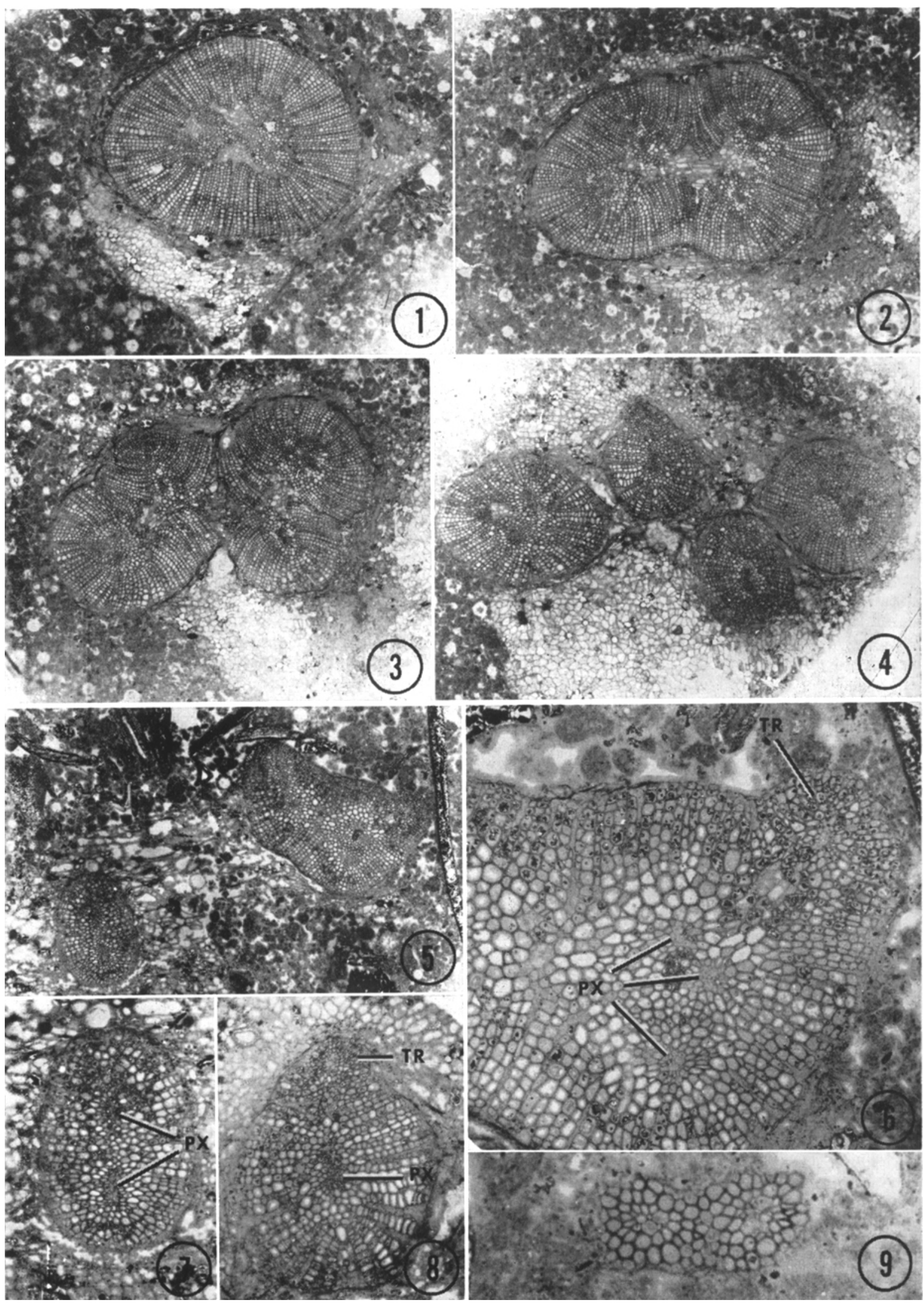




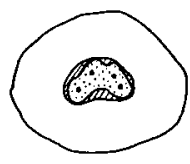

10

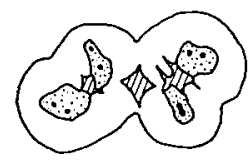

13

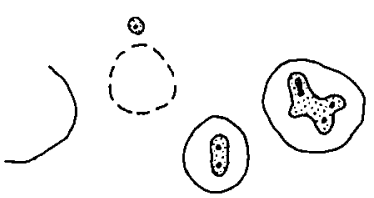

15
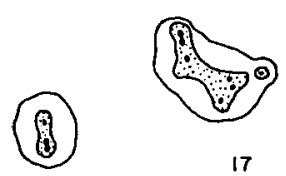

17

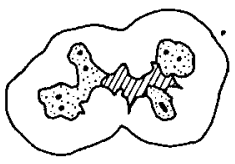

12

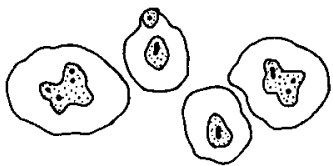

14

$\infty$
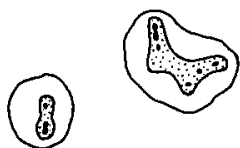

16

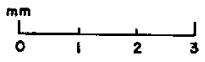

Fig. 10-17. Chapelia campbellii. Camera lucida drawings of transverse sections of the xylem columns showing form, organization of tissues, stelar branching pattern, location and branching of the protoxylem strands and trace origin. Details in the text. Black, protoxylem; stippled, primary xylem; lined, parenchyma; white, secondary xylem.

duced toward the adaxial surface of the specimen, the other toward the abaxial surface. ${ }^{2}$ This results in a rather symmetrical arrangement of two smaller vascular columns bounded laterally by two larger columns (Fig. 4, 14).

Distal to the level of branching the four vascular columns begin to separate laterally. After the inner columns with clepsydroid primary xylem

${ }^{2}$ Our interpretation of the orientation of the frond in relation to the axis on which it was borne is based on the form of the primary xylem strands of the outer vascular columns (see esp. Fig. 5, 16, 17). In fronds of some other genera with primary vascular strands of similar papilionoid form (in transverse section), the broader, U-shaped groove occurs toward the adaxial surface whereas the opposite, narrower groove (where it exists) faces the abaxial surface (see, e.g., Williamson, 1890; Williamson and Scott, 1895; Long, 1963). On the assumption that the strands in our specimen were oriented similarly, all illustrations have been arranged as if the presumed adaxial surface of the frond were in the direction of the top of the page. strands become separated by a distance of about $170 \mu$ (Fig. 15), the rate of their lateral separation decreases abruptly. The outer columns with papilionoid primary xylem strands, on the other hand, continue to become more widely separated from the inner columns (Fig. 5, 16, 17), and in the most apical part of the specimen the two that are preserved are separated by a distance of $1.9 \mathrm{~mm}$

Unfortunately the specimen is not long enough to show complete formation of the axes that will contain the four vascular columns. Two possible patterns of branching can be postulated on the basis of the available evidence. The first, which we feel is more strongly supported, is an equal forking of the axis, each fork being supplied by one of the outer vascular columns. The two inner columns containing clepsydroid strands would both be contained in one axis in the angle of the fork. This axis would probably dichotomize later with each resulting axis being supplied by one of these columns (Fig. 27). The alternate possibility is that a dichotomous branching would occur (indicated by light stippling in Fig. 27), each resulting branch containing an outer papilionoid strand and the adjacent clepsydroid strand, each of which would supply separate axes following an unequal second branching. The result would be four axes, the two outer containing papilionoid vascular strands, the two inner containing clepsydroid strands (Fig. 27). If the latter pattern were to result, one would expect the greater initial separation to occur between the two inner vascular columns. Because they maintain a close proximity to each other while the outer strands separate from them, we feel that the first proposal is more strongly supported.

Trace formation-In the base of the specimen there are only four protoxylem strands, one visible in each lobe of the primary xylem column (Fig. 10, 18). No traces depart from the column prior to its branching, but this does not negate the possibility that pinnae or pinnules were borne on this part of the frond since only a small segment (less than $1 \mathrm{~cm}$ ) was preserved. It is quite possible that traces were produced in this axis at lower levels. Following or during stelar branching, two protoxylem strands develop in the lobes (from which traces will depart) of the papilionoid columns and two in the clepsydroid primary xylem columns (Fig. 10-17). Traces may apparently originate in either of two ways. The terminal

Fig. 1-9. Transverse sections of Chapelia campbellii. PX, protoxylem; TR, trace.-Fig. 1-5. Selected sections from a series showing the general organization of the axis as well as the branching of the stelar column and accompanying changes in the primary and secondary vascular tissues. Slides $5,8,10,11$ and $22, \times 13$. -Fig. 6 . Detail of the xylem of a vascular column with a papilionoid primary xylem strand, showing trace formation and division of the protoxylem (compare with Fig. 16 and 17). Slide 22, $\times$ 46.-Fig. 7, 8. Vascular columns containing clepsydroid primary xylem strands showing, in Fig. 8, trace formation. Slides 22 and 11, $\times 27$.-Fig. 9. Trace, shown in Fig. 8, following branching of the protoxylem. Slide $19, \times 92$. 

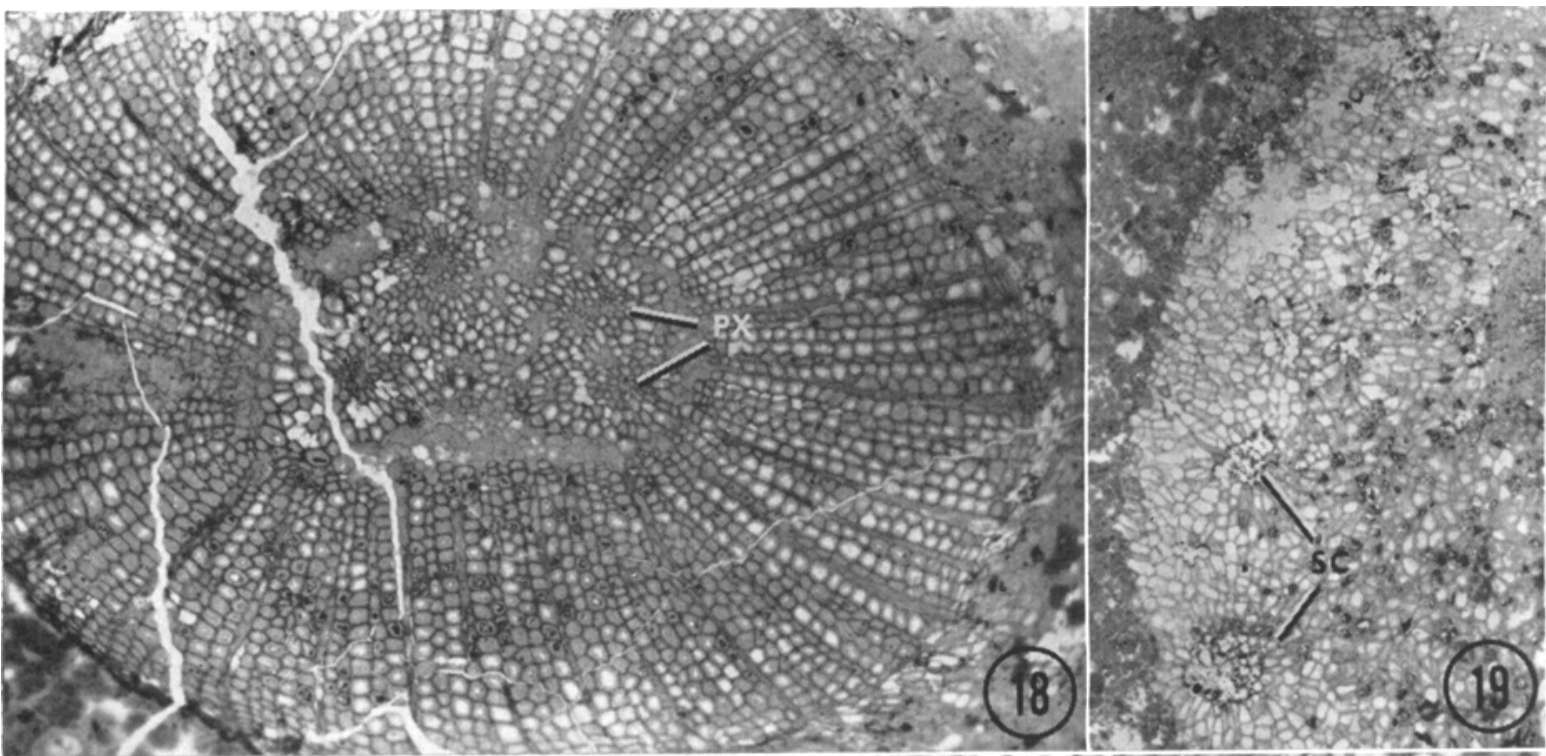

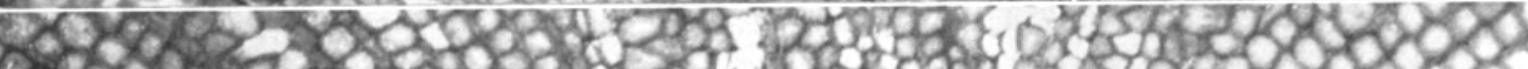

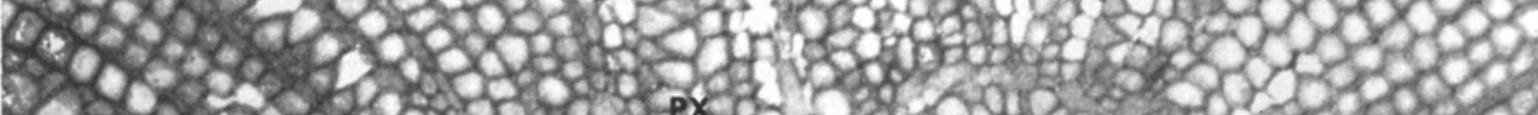

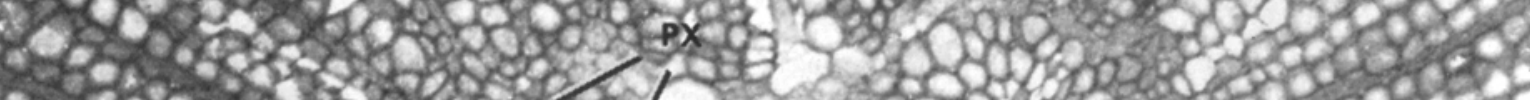
La

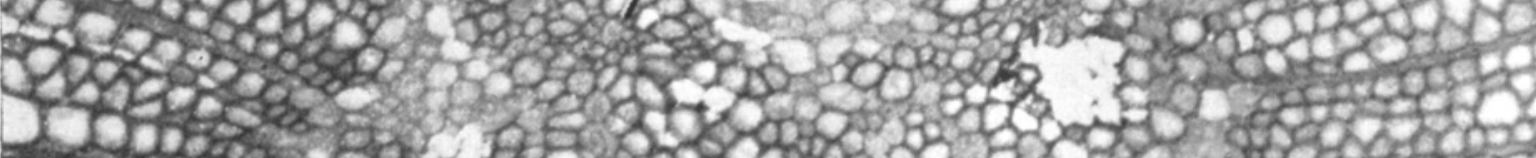

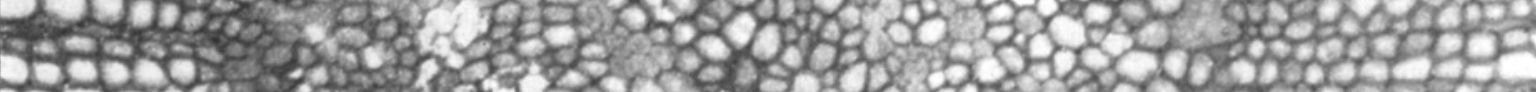
2007 .

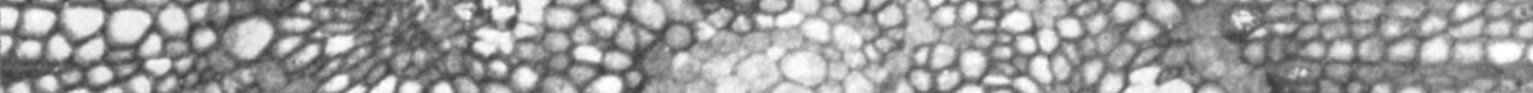

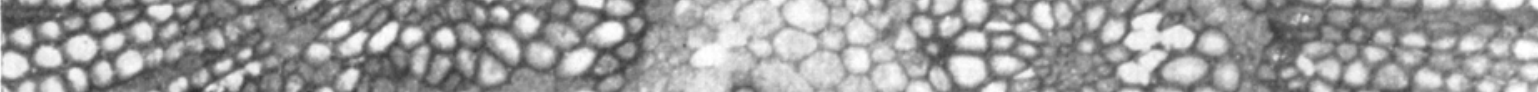

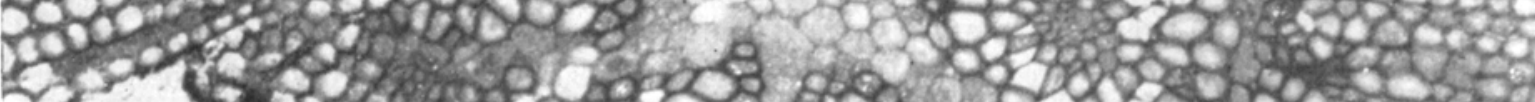

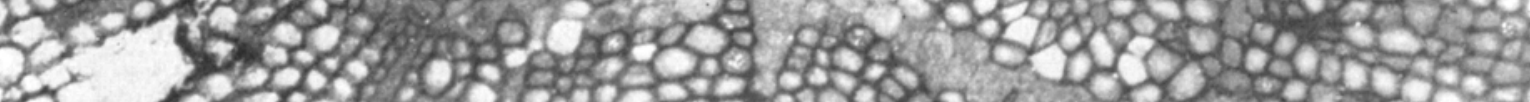
7r. 36 .
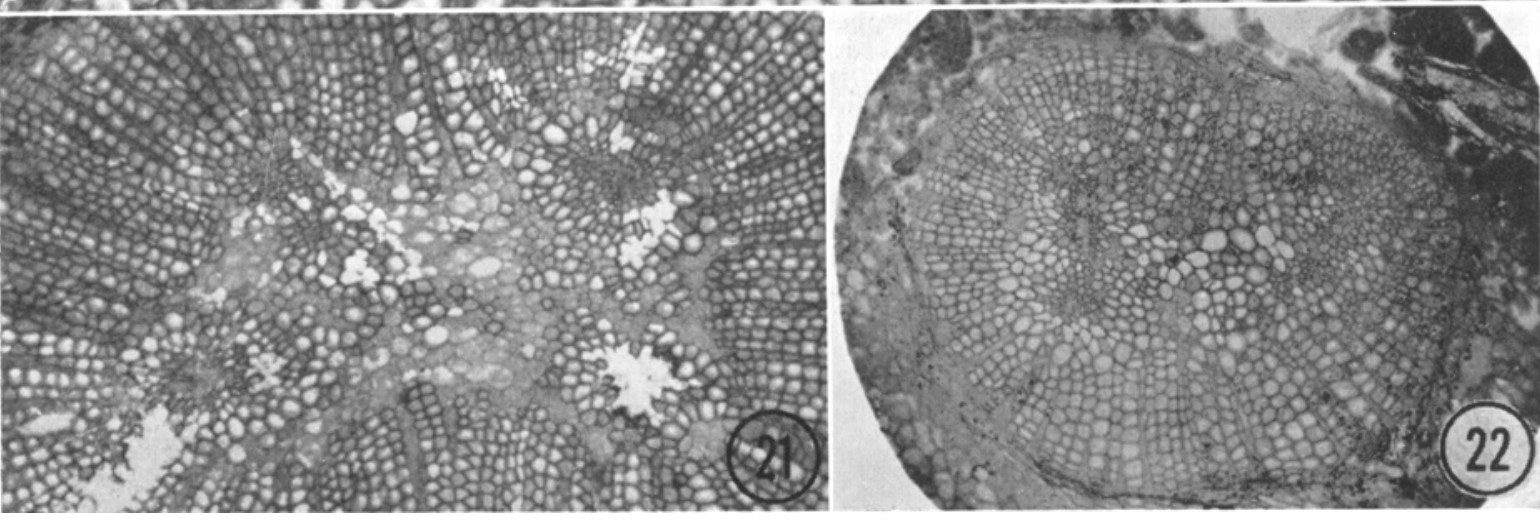
protoxylem of the pair and the surrounding metaxylem may simply branch off as the trace. The remaining protoxylem divides to reconstitute the pair in the lobe (Fig. 6, 16, 17). On the other hand, the terminal protoxylem of the pair may divide, forming three protoxylems in the lobe, or the clepsydroid column. The outer then diverges with metaxylem as the trace, leaving two protoxylems (Fig. 15-17). Unfortunately, the completion of trace-formation by the latter method cannot be observed, but it seems reasonably certain that this interpretation is correct.

In the left side of the papilionoid primary xylem column in Fig. 15-17 the latter sequence described above is clear. The extension of the lobe of the primary xylem toward the periphery of the vascular column in addition to the division of the protoxylem strongly suggests that a trace will branch from this position at a higher level. This is true also of the clepsydroid primary xylem column in Fig. 15-17. Following division of the original single protoxylem (Fig. 4, 15), the abaxial protoxylem begins to elongate and to become two-lobed prior to branching (Fig. 16, 17). In five succeeding sections not illustrated this protoxylem becomes more extended and the adaxial lobe of primary xylem becomes extended nearer to the margin of the secondary xylem, suggesting strongly that a trace will branch from this lobe at a higher level.

Throughout the 30 sections of this specimen, only one trace actually becomes completely free from the parent vascular column of primary and secondary xylem (Fig. 8, 9, 14-16). At progressively higher levels in the cortex, the trace which originally contained only one protoxylem (Fig. $\mathrm{S}, 14,15)$ becomes two-lobed following the branching of the protoxylem (Fig. 9, 16).

If our interpretation is correct, it is apparent that traces depart from both adaxial and abaxial edges of the clepsydroid stelar columns and laterally from the papilionoid columns (Fig. 5, $6,17)$. In view of the fact that the position of the columns following branching suggests that the frond was a flattened structure, the orientation of the clepsydroid strands and the origin of traces from them at right angles to the presumed plane of the frond is rather surprising. It is impossible, however, to know the pattern of disposition of the lateral appendages since nothing is known about the course of the traces following their origin. Traces apparently originate from only the two adaxial lobes of the papilionoid columns, providing them with a bilateral symmetry which, no doubt, was also reflected in the position of the lateral appendages of the rachises which they supplied.

We have seriously considered assigning our specimen to the genus Lyginorachis, established originally by Kidston for detached petioles similar in morphology to petioles of Lyginopteris oldhamia. There are, indeed, many points of resemblance between Chapelia and Lyginorachis. Of more importance, however, are the striking differences such as the clepsydroid primary xylem strands which comprise two of the stelar columns following stelar branching, and the presence in the base of the specimen of a stem-like, lobed protostele. These features are unknown in either Lyginopteris or Lyginorachis. Consequently, we have decided that rather than to expand the concept of Lyginorachis unduly by including in it our specimen, the wiser course would be to establish a new genus.

The generic name, Chapelia, is derived from the collecting locality, Jacobs Chapel. The specific name honors Dr. Guy Campbell of Corydon, Ind., diligent student of the New Albany Shale, whose hospitality, assistance and continuing interest have contributed importantly to this series of papers.

Diagnosis-Chapelia gen. n.-Petiole segment, structurally preserved, from a region of the frond just proximal to petiolar branching. Basal part of the specimen essentially decorticated, about $5 \mathrm{~mm}$ in diam, contains a stem-like, protostelic primary xylem column, four-lobed in transverse section, each lobe containing a single mesarch protoxylem. The primary xylem column branches to form two outer papilionoid strands of bilateral symmetry and two inner clepsydroid strands, the long axes of which in transverse section are oriented at $90^{\circ}$ to the plane of the frond. Mesarch traces probably depart alternately from both edges of the clepsydroid strands; traces originate laterally, being produced alternately, from the two adaxial lobes of the papilionoid strands. Secondary xylem persists throughout the specimen, but decreases distally. Below the level of stelar branching it is separated, in large part, from the primary xylem by parenchyma. Secondary phloem, containing rays and radially arranged thin-walled cells, is bounded by clusters (or bundles?) of thick-walled sclerenchyma cells. Similar clusters of sclerenchyma

Fig. 18-22. Chapelia campbellii. Transverse sections. PX, protoxylem; SC, sclercnchyma.-Fig. 18. Section from near base of the specimen showing primary xylem, vaguely four-lobed, with four distinct protoxylems. Slide 2 , $\times 34 .-$ Fig. base of the specimen showing primary xylem, vaguely four-lobed, with four distinct proser of 19. Cortex contlobed, with mesarch protoxylem. Note also parenchyma within and surrounding primary xylem. Slide 5, tinctly four-lobed, with mesarch protoxylem. Note also parenchyma within and surrounding prith such abundant internal parenchyma that it appears to be separated into two distinct strands. Slide $3, \times 34$.-Fig. 22 . Vascular column, following branching, with papilionoid primary xylem strand. slide $16, \times 28$. 
form a cylinder in the cortex, interior to which are smaller clusters and single cells of sclerenchyma arranged randomly.

Chapelia campbellii sp. n.-The characters of the single species are those of the genus.

Type material-Thirty slides bearing the number 56272 in the Museum of Paleontology of the University of Michigan, Ann Arbor.

Horizon-Falling Run Member of the Sanderson Formation (Upper Devonian or Iswer Mississippian), New Albany Shale.

Discussion-For several reasons we believe the specimen is part of a large frond from just below a level of branching. One of the most important bases for reaching this conclusion is the orientation and retention of four vascular columns in, broadly speaking, one plane following branching. This suggests strongly that the rachises produced will also be oriented in one plane, and that the structure is part of a flattened branch system. A branching pattern of this type is characteristic of many pteridosperm fronds. The apparent bilateral symmetry of the papilionoid strands of primary xylem which develop following branching of the vascular column probably indicates a similar bilateral arrangement of lateral appendages on the rachises which these will supply, and it further supports the view that this specimen is part of a frond. These papilionoid strands resemble those of known petioles and rachises of Lyginopteris, Tetrastichia, Tristichia and Lyginorachis, and the two-lobed trace bearing two protoxylem strands is similar to that of several species of Lyginorachis (see Calder, 1935).

It is already clear that this specimen resembles in many ways petioles of known pteridosperms, or petioles generally believed to be of pteridosperm affinity, and this possible pteridosperm relation-

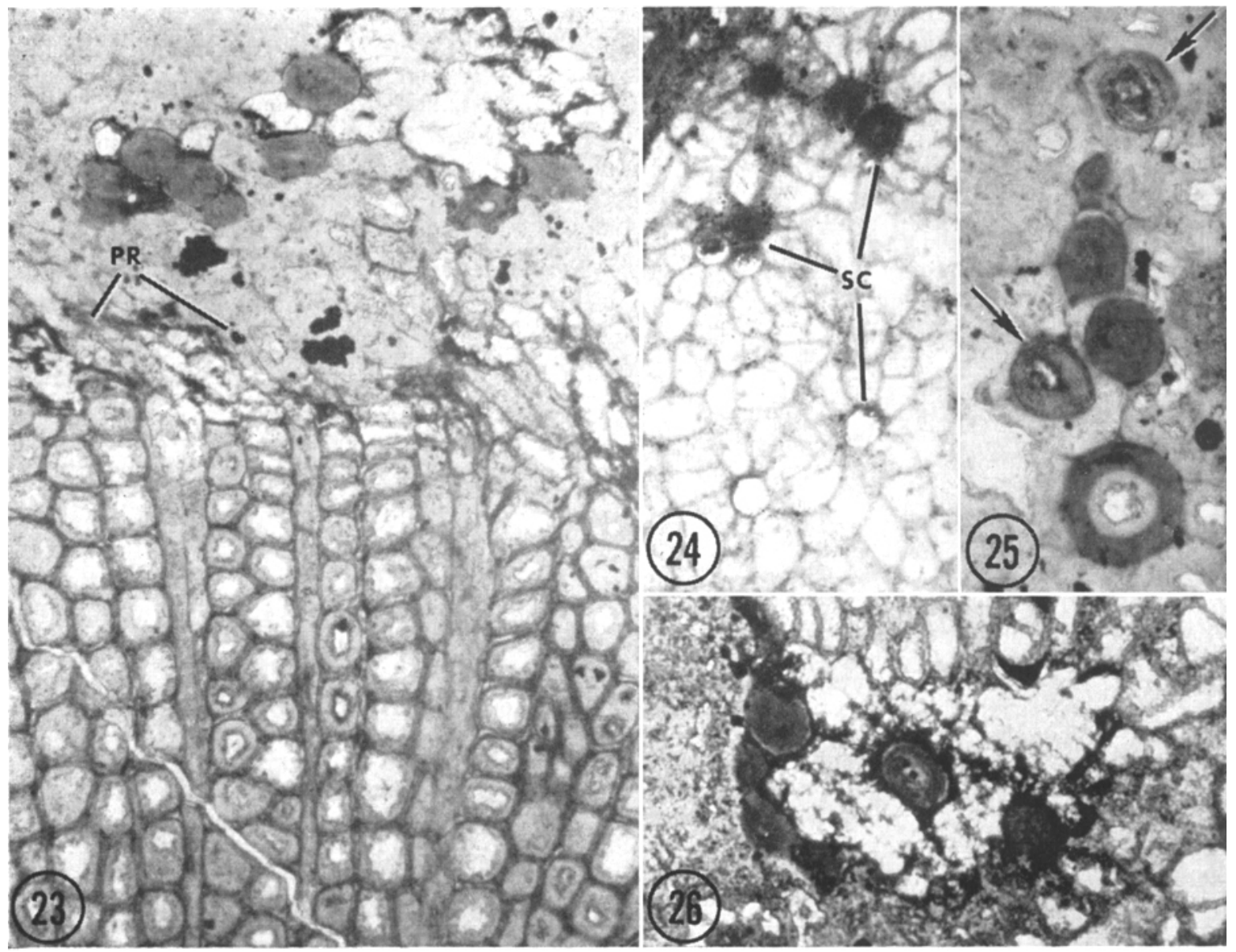

Fig. 23-26. Chapelia campbellii. Transverse sections. PR, phloem ray; SC, sclerenchyma.-Fig. 23. Details of secondary xylem and phloem. The sclerenchyma probably marks the outer boundary of the phloem. Slide $2, \times 130 .-F i g .24-26$. Sclerenchyma in the cortex, showing several stages in degradation of the cell wall.-Fig. 24. Isolated cells and small clusters (or bundles) of sclerenchyma from the inner cortex. When cell wall degradation is extensive the cell appears to have a very thin wall and dark contents. Slide 11, $\times 63 .-$ Fig. 25 . Sclerenchyma cells showing several stages of wall degradation. Slide 22, $\times 168$. - Fig. 26. A large cluster or bundle of sclerenchyma from the outer preserved cortex (see Fig. 19) showing a few cells with preserved thick cell walls. Slide $11, \times 82$. 


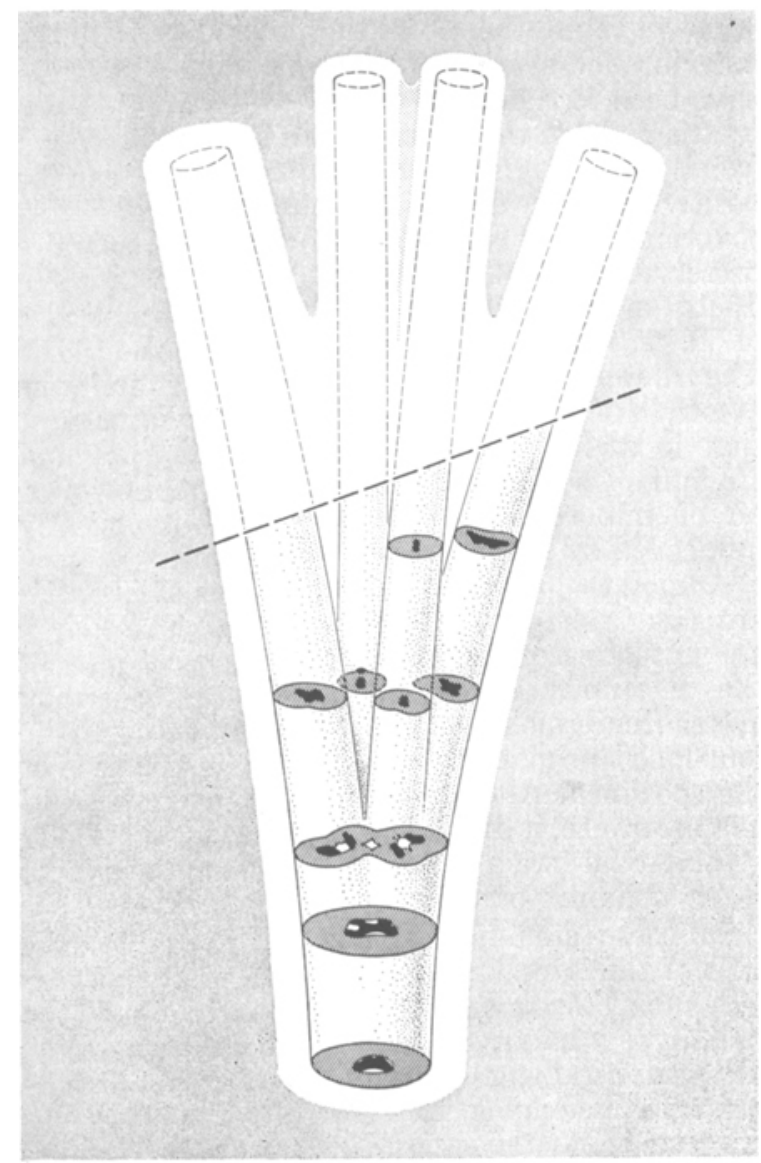

Fig. 27. Chapelia campbellii. Three-dimensional drawing of the specimen emphasizing, below the dashed line, gross morphology of the vascular system and form of the primary xylem. That above the dashed lines represents two possible patterns of branching in this part of the frond (or branch system). See text for explanation. Black, primary xylem; white, parenchyma; lined, secondary xylem.

ship is further supported by certain histological details.

The clusters of sclerenchymatous cells arranged in a cylindrical pattern in the cortex resemble very closely the nests of "sclerotic cells" characteristic of the stems and petioles of Lyginopteris, Tetrastichia, Tristichia and several species of Lyginorachis (e.g., L. papilio [Scott, 1923; Long, 1963], L. waltoni and L. brownii [Calder, 1935]). The single cells and smaller clusters of cells, especially those in which cell wall degradation is great, are similar in appearance to the "secretory sacs" of these plants. It is clear, however, that in Chapelia they are thick-walled sclerenchyma cells of some type and, therefore, most probably not secretory in nature.

The secondary wood exhibits some characteristics which, further, suggest a relationship with primitive cycadophytes. Especially in the outer part it has a distinetly monoxylic nature. The tracheids are relatively thin-walled and of large diameter $(55 \mu)$, and in the peripheral part of the wood many of the rays are biseriate.

In view of the strong evidence of pteridosperm relationship, it is of considerable interest that some prominent features are characteristic of certain members of the Calamopityeae, often considered to be - but as yet not proven to bepteridosperms. In the base of the specimen, for example, the separation of the primary and secondary xylem by parenchyma resembles the condition in stems of Calamopitys and Stenomyelon muratum (Read, 1937). The inclusion of a large amount of parenchyma within the primary xylem is also similar to the condition in Stenomyelon, especially S. muratum and S. heterangioides (Long, 1964), and also of small axes of Calamopitys in which the primary xylem is essentially protostelic. In addition, the form of the primary xylem strand in cross section at the base also resembles that of S. muratum and small axes of Calamopitys.

The fact that the petiole bases attached to stems of Calamopitys and Stenomyelon and the petioles included in the form genus Kalymma are so different from this specimen precludes identification with any of these genera. There are other calamopityeans, however, about whose petiole structure nothing is as yet known. There is no doubt that Chapelia resembles closely some pteridosperm petioles, but no other known petrified petioles exhibit a similar pattern of stelar branching or clepsydroid primary xylem strands. Clepsydroid strands are characteristic of several coenopterid fern genera, e.g., Clepsydropsis, Asterochlaena and Rhacophyton, and are known to occur also in some genera of the Cladoxylales (sec Leclereq and Banks, 1962). It is now apparent that clepsydroid strands were characteristic as well of at least one plant which seems to be of pteridosperm and/or calamopityean affinity.

The possession by Chapelia of some features common to Calamopitys and Stenomyelon supports the view that the latter are related to pteridosperms. If it were not for the fact that these genera are not known to have produced seeds they would certainly be classified with the pteridosperms. Interestingly, no seeds have ever been collected from the New Albany Shale. This is surprising in view of the numerous remains of well-preserved pteridosperm-like calamopityeans that occur in this shale and the occurrence of numerous seeds in association with some of the same, and other, genera in the Lower Carboniferous of Great Britain (sec Long, 1966, for references). It would seem, therefore, that the mere association of seeds with calamopityean genera may be a dangerous basis upon which to assign such genera to the Pteridospermales. It is quite possible that the Upper New Albany Shale is slightly older than the plant-bearing horizons of the British Lower Carboniferous which could account for the absence of seeds. It is possible, therefore, that 
some of these genera, such as Stenomyelon and Calamopitys, common to the British Lower Carboniferous and the New Albany Shale, might be pteridophytes, not seed plants, but possibly closely related and ancestral to some of the pteridosperms.

Although we have been unable to match Chapelia with any known structurally preserved pteridosperm, there are several genera of pteridosperm foliage compressions with which it can be profitably compared. These are Diplothmema zeilleri Stur (see Zeiller, 1886, 1888), Adiantites machaneki Stur (Walton, 1931), Rhacopteris paniculifera Stur (1877), and Diplopteridium teilianum (Walton, 1931), all of Lower Carboniferous age. In all of these except the last, the frond is divided into four major sections either by two dichotomies (as in Diplothmema zeilleri) or by a dichotomy and an unequal branching of each rachis thus formed (as in Adiantites machaneki and Rhacopteris paniculifera). In the division of the fronds into four sections, these species resemble one of the two possible branching patterns of Chapelia. Diplothmema zeilleri differs from Chapelia, however, in that the two successive dichotomies produce four rachises of equal size which form very wide angles. In the occurrence of rachises of unequal size following the second branching, and in the small angle between them, Adiantites machaneki is probably more similar to Chapelia. It differs, however, in that the larger rachises are the inner ones, whereas in Chapelia the larger ones are apparently located on the outside.

The branching pattern of the fertile part of the frond of Rhacopteris paniculifera may also be similar to that of Chapelia, but like Adiantites machaneki it differs in having the two larger rachises interior to the smaller ones. In each of these species, i.e., Diplothmema zeilleri, Adiantites machaneki and Rhacopteris paniculifera, all of the rachises, though differing in size, are otherwise morphologically similar. All in the first two bear vegetative pinnae of the same kind and all in the third bear similar fertile pinnae. On the basis of external morphology one would assume a similar anatomy in all. Its follows, therefore, that rachises differing in anatomy might have had different external morphology and different functions, the one type being vegetative, the other possibly reproductive.

The second possible branching pattern postulated for Chapelia (and more strongly supported by the available evidence) is identical with that of Diplopteridium teilianum. In this species (Walton, 1931) the fertile part of the frond is borne in the angle of the main fork. This fertile part originates as a single axis which later branches. The possession of a morphologically different structure which might have had a different anatomy, as in Chapelia, located between two main vegetative branches of this species suggests to us, therefore, the possibility that the inner branch system of Chapelia might, likewise, have been fertile.

It is possible that Chapelia, in fact, represents a frond of Diplopteridium teilianum. This can be positively determined, of course, only by discovering a frond of $D$. teilianum with structurally preserved axes. One feature which casts some doubt on this possibility is the rather small size of $D$. teilianum as described by Walton (1931). The diameter of the stelar columns and the presence of secondary xylem in Chapelia suggest that it was a somewhat larger frond. Size and amount of secondary tissues may not, however, be of importance since they may be greatly influenced by environmental conditions.

Among the most interesting aspects of Chapelia are its stem-like characteristics. The large amount of secondary xylem in the basal part of the specimen, persisting in lesser quantity even after branching, is very stem-like as is the four-lobed primary xylem column in the base of the specimen. Although somewhat asymmetrical in appearance, it divides as though it were radially symmetrical with alternating lobes becoming stelar columns of equivalent structure.

In these stem-like features it resembles the axes of the lateral branch systems of Aneurophyton and Tetraxylopteris (Beck, 1957) and the radially symmetrical parts of Tristichia ovensi, believed by Long (1963) to be part of fronds probably belonging to Pitys. Long (1963) has suggested that the stems of Tetrastichia (Gordon, 1938) might in fact be frond axes, and this view is further supported by the structure of Chapelia. All of these stem-like frond axes feature a lobed protostele, but in the cauloid petiole of Archaeopteris there is a cylinder of mesarch primary vascular bundles (Carluccio, Hueber, and Banks, 1966).

It seems that we have here a group of progymnosperm and primitive gymnosperm genera in which the distinction between leaf and stem had not become as clearly defined as it is in most living plants. (A parallel situation seems to exist in the fronds of coenopterid ferns.) The "fronds" of these genera seem to represent several intermediate stages in the evolution of the leaf from lateral branch systems.

In Archaeopteris stelar structure of both rachis and pinna axes is radially symmetrical. The fronds are, however, bilaterally symmetrical in part since the pinnae are produced bilaterally, being supplied by traces from opposite lobes of the stele. Traces to the rachial pinnules originate in a helical manner. Although pinnules borne on the pinnae become oriented so that they appear to be oriented in one plane, they are also supplied by traces that arise helically, and are helically attached on the pinnae (Carluccio, Hueber and Banks, 1966).

The fronds of Tristichia, Tetrastichia and 
Chapelia, although of radial symmetry, in part, are distinctly bilateral in part, some frond axes being characterized both by bilaterally symmetrical stelar columns and a bilateral disposition of appendages.

Although we do not mean, necessarily, to imply close evolutionary relationship among the plants we have considered, it seems pertinent to suggest that the condition in Aneurophyton and Tetraxylopteris is clearly the most primitive, that in Archaeopteris probably intermediate, and that in Tristichia, Tetrastichia and Chapelia the most advanced of the group.

\section{IJTERATURE CITED}

Beck, C. B. 1957. Tetraxylopteris schmidtii gen. et sp. nov., a probable pteridosperm precursor from the Devonian of New York. Amer. J. Bot. 44: 350-367.

Calder, M. G. 1935. Further observations on the genus Lyginorachis Kidston. Trans. Roy. Soc. Edinburgh 58: 549-559.

Carluccio, L. M., F. M. Hueber, and H. P. Banks. 1966. Archaeopteris macilenta, anatomy and morphology of its frond. Amer. J. Bot. 53: 719-730.

Crookall, R. 1931. The genus Lyginorachis Kidston. Proc. Roy. Soc. Edinburgh 51: 27-34.

Gordon, W. T. 1938. On Tetrastichia bupatides: a Carboniferous pteridosperm from East Lothian. Trans. Roy. Soc. Edinburgh 59: 351-370.

Leclerce, S., AND II. P. Banks. 1962. Pseudosporochnus nodosus sp. nov., a Middle Devonian plant with cladoxylalean affinities. Palaeontographica 110B: $1-34$.

Long, A. G. 1961. Tristichia ovensi gen. et sp. nov., a protostelic Lower Carboniferous pteridosperm from
Berwickshire and East Lothian, with an account of some associated seeds and cupules. Trans. Roy. Soc. Edinburgh 64: 477-489.

- 1963. Some specimens of Lyginorachis papilio Kidston associated with stems of Pitys. Trans. Roy. Soc. Edinburgh 65: 211-224.

Long, A. G. 1964. Some specimens of Slenomyelon and Kalymma from the Calciferous Sandstone series of Berwickshire. Trans. Roy. Soc. Edinburgh 65: $435-447$.

- 1966. Some Lower Carboniferous fruetifications from Berwickshire, together with a theoretical account of the evolution of ovules, cupules, and carpels. Trans. Roy. Soc. Edinburgh 66: 345-375.

READ, C. B. 1937. The flora of the New Albany shale. Part 2. The Calamopityeae and their relationships. U. S. G. S. Prof. Paper 186-E: 81-104.

ScotT, D. II. 1923. Studies in fossil botany. Vol. II. A. and C. Black, Ltd., London.

Stur, D. 1877. Die Culm Flora des mährischschlesischen Dachschicfers. Abhandl, der Kaiserl. Königl. Geolog. Reichsanst. 8: 1-106.

WALTON, J. 1931. Contribution to the knowledge of Lower Carboniferous plants. III. On the fossil-flora of the black limestones in Teilia Quarry, Gwaenysgor, near Prestatyn, Flintshire, with special reference to Diplopteridium teilianum Kidston sp. (gen. nov.) and some other fern-like fronds. Phil. Trans. Roy. Soc. London 219B: 347-379.

Williamson, W. C. 1890 . On the organization of fossil plants of the Coal Measures. Part XVII. Phil. Trans. Roy. Soc. London 181B: 89-106.

$\longrightarrow$, AND D. H. ScotT. 1895. Further observations on the organization of the fossil plants of the Coal Measures. Phil. Trans. Roy. Soc. London 186B: 703779 .

Zeiller, R. 1886 (Atlas), 1888 (Texte). Flore fossile du Bassin Houiller de Valenciennes. Paris. 